\title{
ECHOCARDIOGRAPHY-ASSISTED SURGERY IN TRANSAORTIC ENDOVASCULAR STENT GRAFTING: ROLE OF TRANSESOPHAGEAL ECHOCARDIOGRAPHY
}

Kazumasa Orihashi, MD

Yuichiro Matsuura, MD

Taijiro Sueda, MD

Masanobu Watari, MD

Kenji Okada, MD

Yuji Sugawara, MD

Osamu Ishii, MD
Objective: Transesophageal echocardiography was applied to visualizing endovascular procedures during transaortic stent grafting for aneurysm and dissection at the distal arch, and the use of transesophageal echocardiography was evaluated.

Methods: The 16 consecutive patients (13 with aneurysms and 3 with dissections) were examined. Transesophageal echocardiography was used for (1) determining graft size, (2) guiding placement of the catheter in the descending aorta at an appropriate position without intimal damage, (3) guiding graft tailoring with a balloon catheter, and (4) examining the results after the procedures.

Results:Visualization was disturbed in one patient who had undergone a previous operation. The graft size was appropriate, except in one patient as a result of underestimation. Transesophageal echocardiography was helpful for navigating the graft placement and tailoring without intimal damage. We tried to keep a distance from the diaphragm of $9 \mathrm{~cm}$ and an attachment portion of $4 \mathrm{~cm}$. In one patient the graft was placed too distally $(7 \mathrm{~cm}$ from the diaphragm) to cover the thick atheromatous plaque with the graft. The patient had paraplegia. Transesophageal echocardiographic assessment of endoleak and thromboexclusion was identical to that of postoperative computed tomography or angiography, with a sensitivity of $100 \%(1 / 1)$ and a specificity of $100 \%(13 / 13)$. Leakage at the proximal suture and graft kinking were found in 3 patients. Successful thromboexclusion by transesophageal echocardiographic assessment (13 patients) was predictive of subsequent regression of aneurysm and dissection in the midterm follow-up period: there was complete and partial regression in 5 and 8 patients, respectively.

Conclusion: Transesophageal echocardiography enables echocardiographyassisted operations with secure step-by-step endoluminal procedures and immediate intraoperative assessment, which is predictive of the postoperative results. (J Thorac Cardiovasc Surg 2000;120:672-8)
$\mathrm{E}_{\mathrm{a}}^{\mathrm{n}}$ ndovascular stent grafting through a transcatheter approach has become popular for treating aortic

From the First Department of Surgery, Hiroshima University School of Medicine, Hiroshima, Japan.

Received for publication Jan 26, 2000; revisions requested March 31, 2000; revisions received May 2, 2000; accepted for publication May 25, 2000.

Address for reprints: Kazumasa Orihashi, MD, First Department of Surgery, Hiroshima University School of Medicine, Kasumi 1-23, Minami-ku, Hiroshima 734-8551, Japan (E-mail: kaori@mcai.med.hiroshima-u.ac.jp).

Copyright (C) 2000 by The American Association for Thoracic Surgery

0022-5223/2000 $\$ 12.00+0 \quad \mathbf{1 2 / 1 / 1 0 9 2 3 7}$

doi:10.1067/mtc.2000.109237 aneurysm, Stanford type B dissection of the proximal descending aorta, or both. ${ }^{1,2}$ It covers aneurysms adjacent to the left subclavian artery (SCA) with a short proximal neck. When graft deployment adjacent to the left SCA causes malperfusion, transposition of the SCA and common carotid artery is added. ${ }^{2}$ Surgical endovascular stent grafting through a midsternal approach is indicated in cases of aneurysm or dissection adjacent to or involving the left SCA (Fig 1), ${ }^{3,4}$ especially when associated surgery, such as coronary artery bypass grafting $(\mathrm{CABG})$, is necessary. Because lung compression through the left thoracotomy is spared, lung damage is minimal. Compared with the conventional aortic replacement through the midsternal approach, distal 


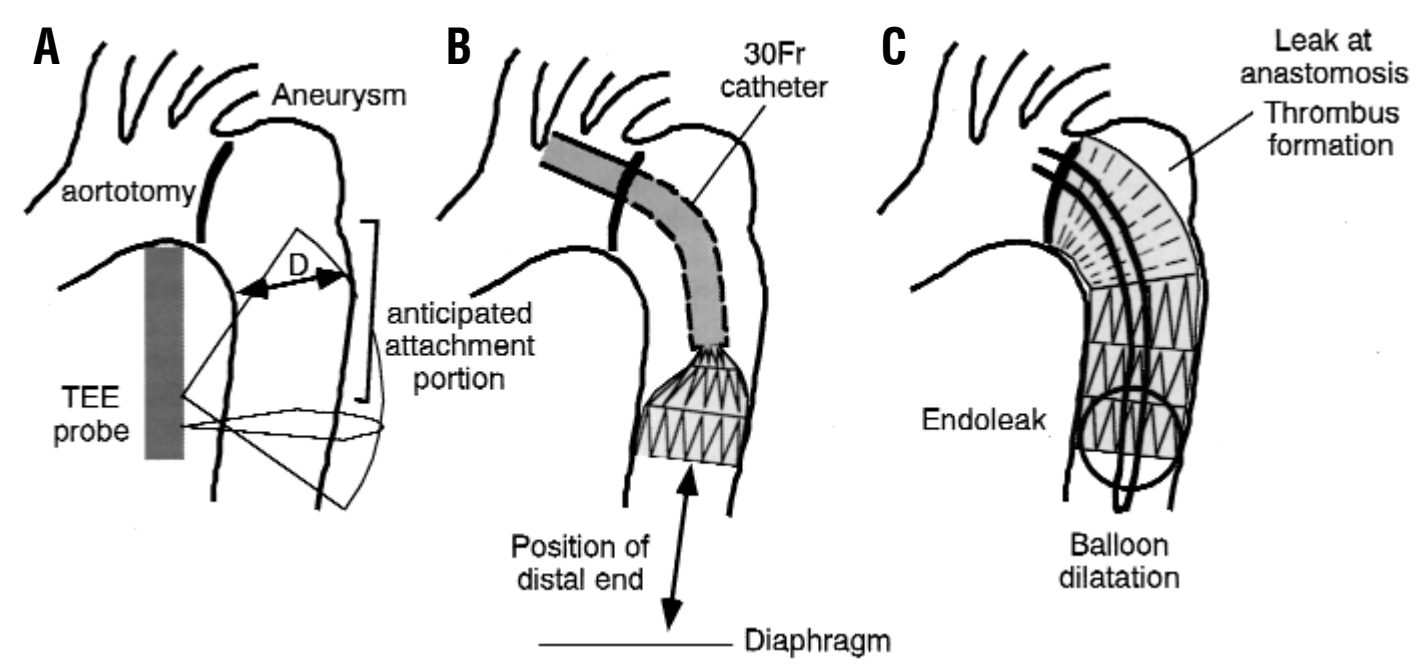

Fig 1. Schematic illustration of procedures and use of TEE in surgical endovascular stent grafting.

anastomosis in the deep and poor visual field is omitted, reducing time and bleeding at the distal anastomosis. Associated surgery is done while the patient is cooled. Left-to-right SCA bypass is added as needed.

However, manipulation of the catheter in the aorta is invisible and could damage the intima. When the result is suboptimal (eg, endoleak or inappropriate graft position), it is diagnosed postoperatively. Fluoroscopy, which is often used in transcatheter procedures, ${ }^{1,2}$ cannot detect intimal damage caused by catheter manipulation.

These problems can be solved with an appropriate imaging modality. We have introduced transesophageal echocardiography (TEE) to visualize endovascular devices, as well as the aorta. In this article our initial experience is reported, with discussion on the merits and problems of using TEE.

\section{Methods}

We examined 16 consecutive patients who underwent transaortic endovascular stent grafting since 1997 (13 men and 3 women; age range $24-83$ years; Table I). Thirteen patients had aneurysms, and 3 had dissections, both of which were adjacent to or involving the left SCA with little proximal neck. Six patients were over 75 years of age, and 7 needed associated surgery, including $\mathrm{CABG}$ and replacement of the ascending aorta, aortic arch, or both. In 3 patients rightto-left SCA bypass was added.

Surgical procedures. A stent-graft was prepared with a Gianturco self-expandable stainless steel Z-stent (Cook Inc, Bloomington, Ind) and a vascular prosthesis (Intervascular Inc, Clearwater, Fla), as reported previously. ${ }^{4}$ The graft size was determined on the basis of the computed tomography (CT) and TEE data, and a graft of 0 to $4 \mathrm{~mm}$ larger in size was used. Associated surgical procedures were completed while the patient was cooled to a rectal temperature of $25^{\circ} \mathrm{C}$. The stent-graft was loaded in a $30 \mathrm{~F}$ catheter before aortotomy. Under circulatory arrest with selective cerebral perfusion established, the anterior wall of the aorta was incised by half of its circumference at just distal to the SCA (Fig 1, A). The aorta was transected in patients with aortic dissection or total arch replacement. The catheter was inserted into the descending aorta, and the graft was pushed out of the catheter (Fig 1, $B)$. After the distal stented portion expanded, excessive unstented graft out of the aortotomy was cut off. The proximal end was sutured to the aortic wall; the posterior half was sutured with the inclusion method, and the anterior half was sutured to the incised edge of the aorta. In cases of aortic dissection, the transected aortic wall was reinforced between the internal graft and an external felt strip. Cardiopulmonary bypass was resumed after the aortotomy was closed (Fig 1,C).

Use of TEE. A 5-MHz biplane TEE (EUB-555, Hitachi Co, Tokyo, Japan) was instituted and used for intraoperative routine monitoring, as well as for this procedure. Transverse and longitudinal views were simultaneously displayed side by side (Fig 2). The aortic intima was examined for fragile plaques, and the internal diameter at the anticipated attachment portion was measured before circulatory arrest (Fig 1, $A$ ). When the cross section of aorta was not round, as in cases of dissection, the circumference was measured, and the diameter was calculated. In visualizing the aorta exactly in the short axis, the TEE probe was manipulated so that the corresponding long-axis view was depicted as coursing horizontally on the display.

The catheter introduced into the aorta was depicted as a strongly echogenic line accompanied by an acoustic shadow, ${ }^{5}$ with the stent-graft packed inside (Fig 2). When the catheter tip was directed to the aortic wall or the intimal flap and could cause damage, the catheter was reshaped and inserted again. The distal end of the graft was located by measuring the distance from the diaphragm. After the 
Table I. Profiles, TEE findings, and postoperative assessment

\begin{tabular}{|c|c|c|c|c|c|c|c|}
\hline $\begin{array}{c}\text { Patient } \\
\text { No. }\end{array}$ & $\begin{array}{l}\text { Age } \\
(y)\end{array}$ & Sex & Disease & $\begin{array}{c}\text { Associated } \\
\text { operation }\end{array}$ & $\begin{array}{c}\text { Graft } \\
\text { size } \\
(\mathrm{mm})\end{array}$ & $\begin{array}{c}\text { Aortic } \\
\text { diameter } \\
(\mathrm{mm})\end{array}$ & $\begin{array}{c}\text { Position } \\
\text { of stent } \\
(\mathrm{cm})\end{array}$ \\
\hline 1 & 64 & $\mathrm{M}$ & $\mathrm{AN}$ & $\mathrm{CABG}$ & 28 & 27 & $>9$ \\
\hline 2 & 79 & $\mathrm{M}$ & $\mathrm{AN}$ & None & 28 & 27 & $>9$ \\
\hline 3 & 65 & $\mathbf{M}$ & $\mathrm{AN}$ & CABG & 32 & 31 & $>9$ \\
\hline 4 & 72 & $\mathrm{~F}$ & DIS & $\mathrm{CABG}$ & 22 & 20 & $>9 *$ \\
\hline 5 & 47 & $\mathrm{M}$ & DIS & A-AO/ARCH & 24 & 22 & $>9$ \\
\hline 6 & 78 & $\mathrm{M}$ & $\mathrm{AN}$ & None & 28 & 28 & $>9$ \\
\hline 7 & 64 & $\mathbf{M}$ & $\mathrm{AN}$ & RSCA-LSCA & 26 & 25 & $>9$ \\
\hline 8 & 24 & $\mathrm{M}$ & DIS & A-AO/ARCH & NA & NA & NA \\
\hline 9 & 65 & $\mathrm{~F}$ & $\mathrm{AN}$ & - & 24 & 23 & $>9$ \\
\hline 10 & 76 & $\mathbf{M}$ & $\mathrm{AN}$ & CABG, TAP & 30 & 29 & $9 \dagger$ \\
\hline 11 & 56 & $\mathrm{M}$ & $\mathrm{AN}$ & $\mathrm{CABG}, \mathrm{ARCH}$ & 30 & 27 & $7 \ddagger$ \\
\hline 12 & 83 & $\mathbf{M}$ & AN & None & 32 & 30 & $>9$ \\
\hline 13 & 75 & $\mathrm{~F}$ & $\mathrm{AN}$ & None & 30 & 26 & $>9$ \\
\hline 14 & 76 & $\mathbf{M}$ & AN & None & 32 & 30 & $>9 \S$ \\
\hline 15 & 70 & M & $\mathrm{AN}$ & RSCA-LSCA & 28 & 28 & $>9$ \\
\hline 16 & 69 & $\mathrm{M}$ & $\mathrm{AN}$ & RSCA-LSCA & 28 & 26 & $>9$ \\
\hline
\end{tabular}

$D S A$, Digital subtraction angiography; $A N$, aneurysm; $C R$, complete regression; $N A$, not applicable; $D I S$, dissection; $A-A O$, ascending aorta replacement; $A R C H$, total arch replacement; $R S C A-L S C A$, right subclavian-left subclavian artery bypass; $P R$, partial regression; TAP, tricuspid annuloplasty.

*Graft tip $5 \mathrm{~cm}$ from celiac trunk, pulled by $8 \mathrm{~cm}$.

$\dagger$ Graft tip $7 \mathrm{~cm}$ from diaphragm, pulled by $2 \mathrm{~cm}$.

¥Intentionally low to avoid intimal injury, abnormally low on postoperative chest $\mathrm{x}$-ray film.

$\S$ Appears abnormally low on postoperative chest $\mathrm{x}$-ray film caused by tortuous course of the aorta.

$\|_{\text {Early brain death. }}$

diaphragm was visualized at the center in a longitudinal scan, the probe was withdrawn until the graft tip was visualized at the center. The difference of depths of the TEE probe between these 2 levels was defined as the distance from the diaphragm (Fig 1,B). When not clearly visualized, the celiac trunk was visualized as reported before ${ }^{6}$ and was used as another reference. The length of the attachment portion was defined as the distance between the distal end of the aneurysm or entry site and the graft tip. We tried to leave an attachment portion of $4 \mathrm{~cm}$ or longer and maintain the distance from the diaphragm at $9 \mathrm{~cm}$ or longer (approximately 3 vertebrae). Attachment of the graft to the aortic wall was assessed as adequate when there was no gap (B mode) without a flow signal (color Doppler mode) between them. When the distal end of the graft was curved inward, it was reformed with balloon inflation by using a Foley balloon catheter located and inflated under TEE guidance to avoid an intimal injury (Fig 3). The result was immediately assessed, and dilatation was added if necessary.

As systemic circulation resumed, endoleak at the distal end and leakage at the proximal suture into the residual aneurysmal lumen were examined. Thromboexclusion was assessed as successful when spontaneous echocardiographic contrast appeared without a detectable flow signal in the excluded lumen. The stentless portion of the graft was examined for stenosis or twisting.

Postoperative assessments. The position of the stent was examined by chest radiography in the intensive care unit. The following assessments were made with CT, angiography, or both: (1) adequacy of graft size; (2) endoleak; (3) leak at the proximal anastomosis; (4) stenosis at the stentless portion; and (5) thrombosis exclusion.

\section{Results}

No complication related to the use of TEE was encountered. The descending aorta was clearly visualized, except in patient 8 , who had previous replacement of the descending aorta. This patient is excluded from analysis hereafter. We had one operative death (patient 3) caused by broad cerebral infarction, which was probably caused by embolism of debris from the iliac artery, and two late deaths unrelated to the operation: patient 6 died as a result of aspiration pneumonia, and patient 14 died as a result of cerebral infarction caused by hypotension on arrival. Airway bleeding was not encountered, except in patient 14 , who had hemoptysis preoperatively.

The aortic diameter varied from 20 to $30 \mathrm{~mm}$, and the graft size was 22 to $32 \mathrm{~mm}$ (Table I). Intimal injury during catheter insertion or balloon inflation was not seen in any patient. The distal end of the graft was at 9 $\mathrm{cm}$ or farther from the diaphragm, except in patient 11, in whom a thick atheromatous plaque was found at the proximal descending aorta. The graft was intentionally implanted more distally than usual to cover this portion with the graft so that the graft might not dig into the 


\begin{tabular}{|c|c|c|c|c|c|c|}
\hline $\begin{array}{c}\text { Attachment } \\
\text { portion } \\
(\mathrm{cm}) \\
\end{array}$ & $\begin{array}{c}\text { Endoleak } \\
\text { TEE/CT, } \\
\text { DSA }\end{array}$ & $\begin{array}{c}\text { Leak (proximal) } \\
T E E / C T \\
D S A \\
\end{array}$ & $\begin{array}{c}\text { Stenosis } \\
\text { TEE/CT, } \\
\text { DSA }\end{array}$ & $\begin{array}{l}\text { Flow in } \\
\text { residual } \\
\text { lumen }\end{array}$ & $\begin{array}{c}\text { Postoperative } \\
\text { thrombosis } \\
(C T, D S A)\end{array}$ & Prognosis \\
\hline$>5$ & $-1-$ & $-1-$ & $-1-$ & - & + & CR 16 mo \\
\hline$>5$ & $-1-$ & $-1-$ & $-1-$ & - & + & CR 18 mo \\
\hline$<3$ & $+/ \mathrm{NA}$ & $-/ \mathrm{NA}$ & $-/ \mathrm{NA}$ & + & $\mathrm{NA} \|$ & Early death \\
\hline$>5$ & $-1-$ & $-1-$ & $-1-$ & - & + & CR 4 mo \\
\hline 5 & $-1-$ & $+1-$ & $-1-$ & +- & + & $\mathrm{CR} 8 \mathrm{mo}$ \\
\hline Gap & $+/+$ & $+/+$ & $-1-$ & + & - & Late death \\
\hline 4 & $-1-$ & $-1-$ & $+/+$ & - & + & PR \\
\hline NA & NA & NA & NA & NA & NA & NA \\
\hline$>5$ & $-1-$ & $-1-$ & $-1-$ & - & + & PR \\
\hline$>5$ & $-1-$ & $-1-$ & $-1-$ & - & + & $\mathrm{CR} 2 \mathrm{mo}$ \\
\hline$>5$ & $-1-$ & $-1-$ & $+1-$ & - & + & Paraplegia \\
\hline 5 & $-1-$ & $-1-$ & $-1-$ & - & + & PR \\
\hline$>5$ & $-1-$ & $-1-$ & $-1-$ & - & + & PR \\
\hline$<3$ & $-1-$ & $-1-$ & $+1-$ & - & + & Late death \\
\hline$>5$ & $-1-$ & $-1-$ & $-1-$ & - & + & PR \\
\hline 5 & $-1-$ & $+1-$ & $-1-$ & +- & + & PR \\
\hline
\end{tabular}

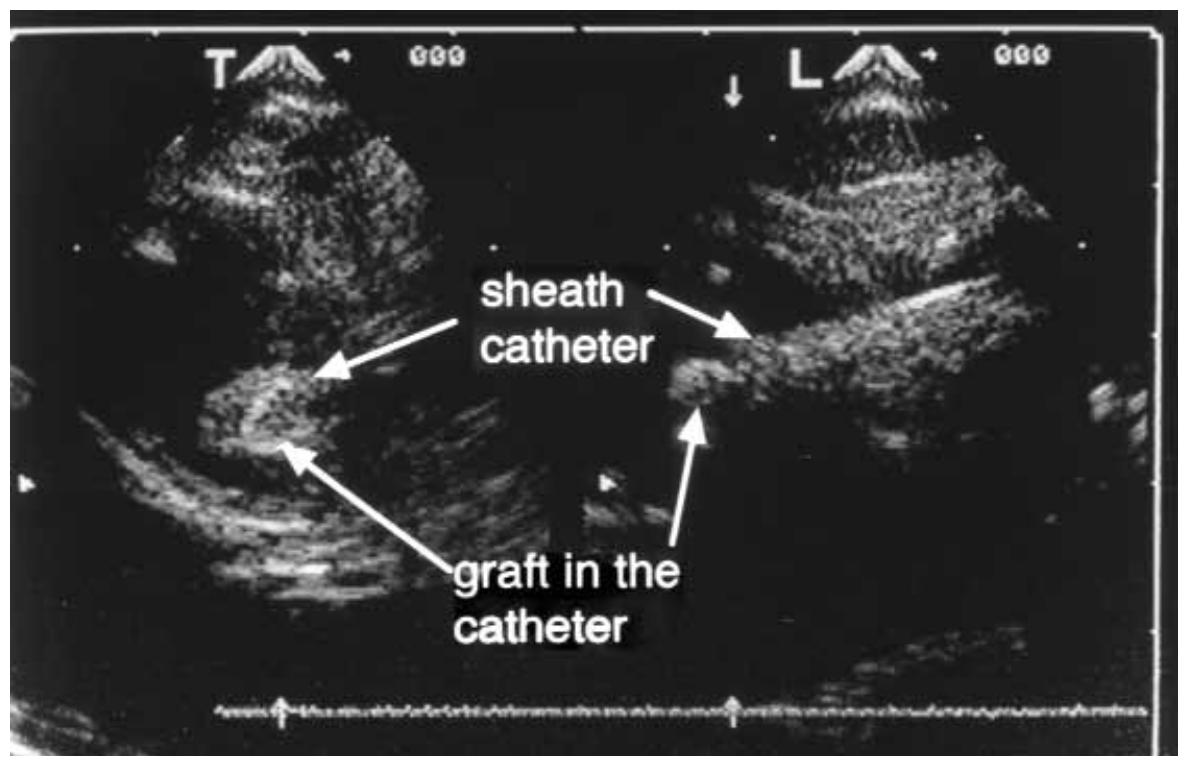

Fig 2. Transesophageal echocardiogram showing a catheter with the stent-graft inside, entering the thoracic descending aorta. The catheter is depicted as strongly echogenic and accompanied by an acoustic shadow.

atheromatous plaque. However, paraplegia developed postoperatively in this patient. In early patients the position of the catheter tip was not determined before releasing the graft. In patient 4 the graft tip was found at only $5 \mathrm{~cm}$ from the celiac trunk. The graft was pulled by $8 \mathrm{~cm}$, leaving the attachment portion longer than 5 $\mathrm{cm}$. In patient 11 the graft was $7 \mathrm{~cm}$ from the diaphragm for the above-mentioned reason. The surgeon was concerned about possible obstruction of the artery of Adamkiewicz and tried to withdraw the graft. However, the graft did not move, probably because the graft size was $3 \mathrm{~mm}$ larger than the aortic diameter. In subsequent patients the catheter tip was located before graft deployment. The postoperative chest $\mathrm{x}$-ray film 


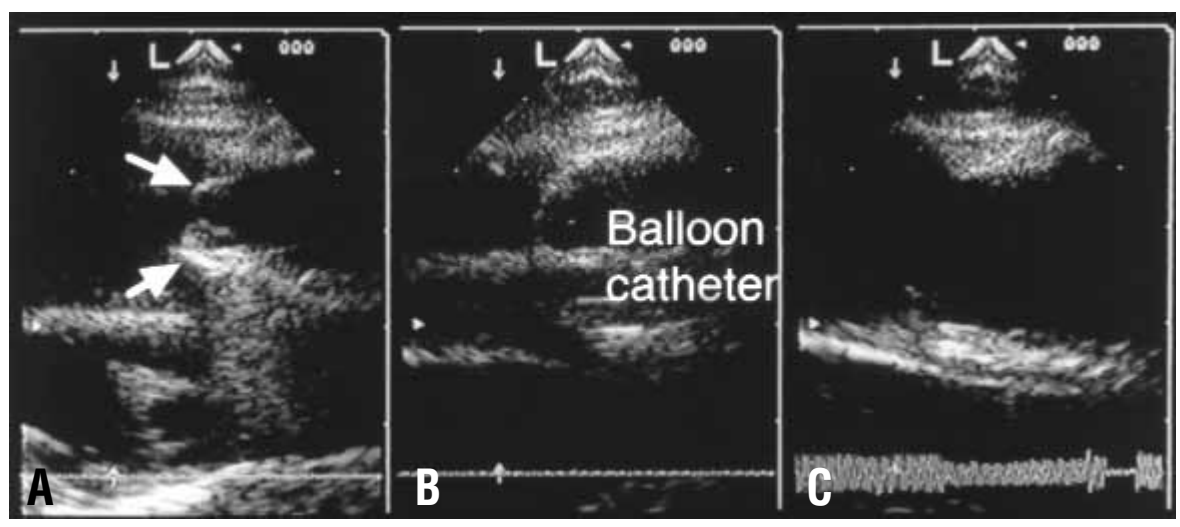

Fig 3. Transesophageal echocardiogram showing correction of inward coil-up of distal end of the stent by using a balloon catheter. A, Graft edge is bent inward; $\mathbf{B}$, balloon inflation; $\mathbf{C}$, graft edge is flat.
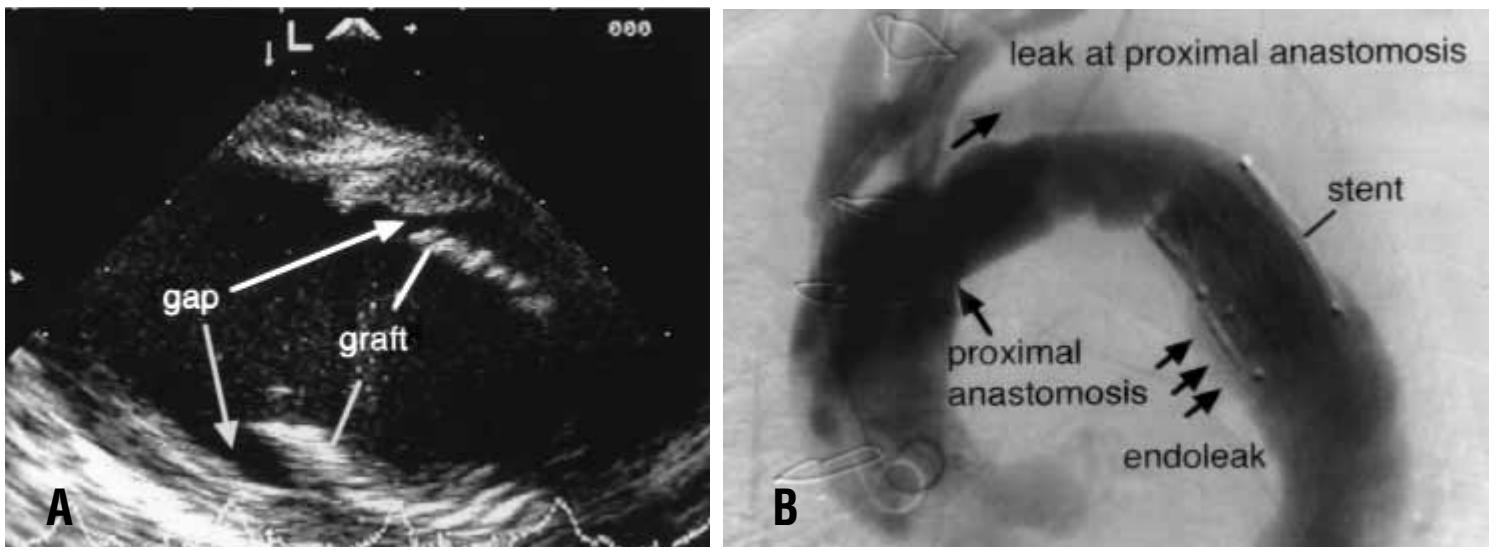

Fig 4. A, Transesophageal echocardiogram showing a gap between the graft and aortic wall. B, Leak at proximal anastomosis and around the stented graft in patient 6 .

depicted the stent within the proximal half of the descending thoracic aorta, except in patients 11 and 14. In the latter a tortuous aorta was responsible while the graft was $10 \mathrm{~cm}$ away from the hiatus.

The attachment portion was longer than $5 \mathrm{~cm}$, except in 3 patients. In patient 6 a gap around the graft was apparent (Fig 4, A; endoleak). In patients 3 and 14 the attachment portion was short. Minor leakage at the proximal suture, stenosis at the stentless portion, and flow in the residual lumen were found in 3,3 , and 4 (apparent in 2) patients, respectively.

Postoperative assessment was available, except in 1 case of early death (patient 3). The graft size was appropriate, except in patient 6 who had endoleak and leakage at the proximal suture (Fig 4, B).
Thromboexclusion was successful in 13 patients and unsuccessful in 1 patient. This result was compatible with TEE assessment, with both a sensitivity and specificity of $100 \%$. Proximal leakage or kinking of the graft was detected in 1 of 3 patients with positive TEE findings. Specificity was $100 \%$ for both.

Among 13 patients with successful thromboexclusion, 5 patients showed complete regression of aneurysm dissection during the follow-up period of 6 to 31 months. Aneurysm disappeared in patients 1, 2, and 10 after 16, 18, and 2 months, respectively, whereas thrombosed false lumen disappeared in patients 4 and 5 after 4 and 8 months, respectively (Fig 5). The size of the aneurysm is regressing in all of the remaining 8 patients. 

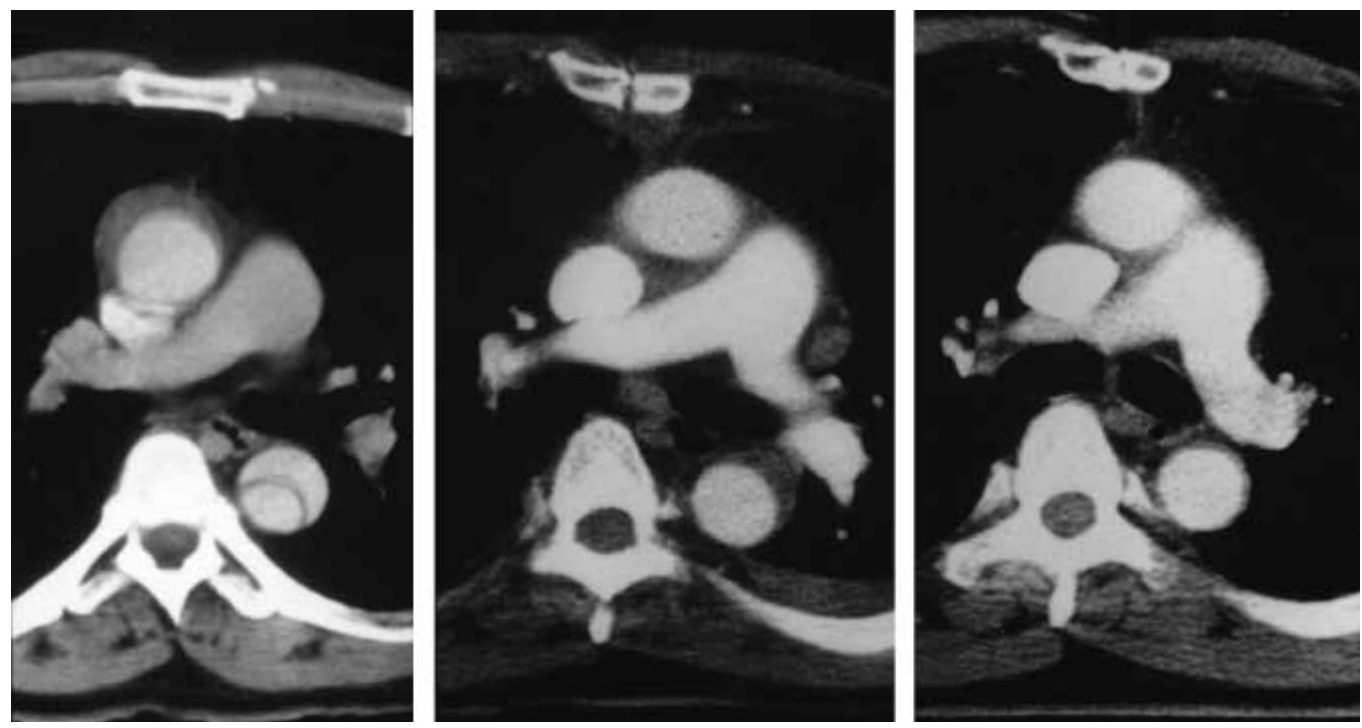

Fig 5. Transesophageal echocardiogram of false lumen in patient 5 . The false lumen with blood flow preoperatively (left) was thrombosed after stent grafting (center). The lumen disappeared 8 months later (right).

\section{Comment}

This study has clarified the merits and limitations of using TEE during transaortic stent grafting. Roles of TEE include the following: (1) to provide morphologic information, such as aortic dimension and condition of the aortic intima before procedures; (2) to visualize endovascular procedures that are not visible from the surgical field, enabling echocardiography-assisted surgery; and (3) to assess the result of procedures in the operating room.

The first key to a good result is to determine an optimal graft size. An inappropriately small graft causes endoleak. The aorta may be depicted as elliptical in the CT images, either scanned obliquely or really deformed. Simultaneous display of orthogonal views was helpful to obtain a real short-axis view. In the transcatheter procedures, a graft of $10 \%$ to $20 \%$ or 2 to $3 \mathrm{~mm}$ larger in size than the aortic diameter is commonly used so that the graft presses against the aortic wall firmly enough to be fixed. In our procedures, however, a graft of only 1 or $2 \mathrm{~mm}$ larger in size than the aortic diameter was mainly used because the graft is sutured to the aorta at the proximal side, and minimal expansion enough to eliminate endoleak is needed. Consequently, the results were acceptable with regression of excluded lumen, except in patient 6 . In this patient aortic diameter was underestimated because it was measured at the top of the atheromatous plaque. This experience led us to measure the diameter at the layer of the tunica media.
The second key is safe and reliable procedures with TEE navigation. They are no longer blind manipulations. However, it is essential for the surgeon and TEE operator to collaborate, and a learning curve is present. The TEE operator needs to know the procedures and visualize the events without delay. The surgeon needs to understand the characteristic images of catheters; that is, the entire portion is not depicted, but only its surface is depicted as echogenic. ${ }^{5}$ The images are cross-sectional, and anything out of the scanning plane is not visualized. Until real-time 3-dimensional TEE becomes available, simultaneous display of transverse and longitudinal views is helpful. It depicts short- and long-axis views of graft and instruments and spares time to switch the scanning planes. One can watch either or both views as needed.

There is no criteria on how deeply the graft can be safely advanced without an occurrence of paraplegia or how long the attachment portion should be to avoid endoleak. From our initial experience in this series, we would recommend placing the graft $9 \mathrm{~cm}$ or longer from the diaphragm (around Th9 level) and keeping an attachment portion longer than $4 \mathrm{~cm}$ because we obtained an acceptable result as long as these criteria are met.

Another feature of TEE is intraoperative assessment. The intraoperative TEE findings on thromboexclusion-endoleak were predictive to the prognosis. When aneurysm or false lumen is successfully thromboexcluded, it regresses and even disappears in the 
midterm follow-up period. The leakage at the proximal suture and graft kinking was rather overestimated or might have alleviated by the time of postoperative assessment.

We conclude that TEE facilitates surgical endovascular stent grafting, especially in determining the graft size, navigating endovascular procedures, and assessing the results immediately after these procedures. Intraoperative assessment is predictive of the postoperative result.

\section{REFERENCES}

1. Mitchell RS, Dake MD, Semba CP, Fogarty TJ, Zarins CK, Liddell RP, et al. Endovascular stent-graft repair of thoracic aortic aneurysms. J Thorac Cardiovasc Surg 1996;111:1054-62.

2. Moon MR, Mitchell RS, Dake MD, Zarins CK, Fann JI, Miller
DC. Simultaneous abdominal aortic replacement and thoracic stent-graft placement for multilevel aortic disease. J Vasc Surg 1997;25:332-40.

3. Kato M, Ohnishi K, Kaneko M, Ueda T, Kishi D, Mizushima T, et al. A new graft-implanting method for thoracic aortic aneurysm or dissection using a stented graft. Circulation 1996;94(Suppl II):II-188-93.

4. Sueda T, Watari M, Orihashi K, Shikata H, Matsuura Y. Endovascular stent-grafting via the aortic arch for chronic aortic dissection combined with coronary artery bypass grafting. J Thorac Cardiovasc Surg 1999;117:825-7.

5. Orihashi K, Oka Y. Cannulae. In: Oka Y, Goldiner PL, editors. Transesophageal echocardiography. Philadelphia: JB Lippincott; 1992.

6. Orihashi K, Matsuura Y, Sueda T, Shikata H, Morita S, Hirai S, et al. Abdominal aorta and visceral arteries visualized with transesophageal echocardiography during operations on the aorta. J Thorac Cardiovasc Surg 1998;115:945-7.

\section{THE THORACIC SURGERY FOUNDATION FOR RESEARCH AND EDUCATION}

\section{Kennedy School Sabbatical}

The Thoracic Surgery Foundation for Research and Education announces that applications for a year-long sabbatical to do graduate studies in health care policy at Harvard University's Kennedy School of Government are now available. Candidates will be accepted early on a rolling admission basis by the graduate school, and scholarships will be awarded by The Foundation's Education Committee. The Kennedy School will review completed applications for the program starting January 3, 2001, and is prepared to make decisions on applications within two weeks of their receipt. The Foundation will make a decision on applications for Alley-Sheridan Scholarships within two weeks of their receipt to The Foundation office. If an interested surgeon has applied to the Kennedy School very early in January, it is possible to have the admissions and scholarship decisions completed by February 1. Please call Lainie Castle at The Foundation office for more information at 312-644-6610, extension 4798.

\section{TSFRE Grateful Patient Program}

One of The Foundation's primary fund-raising goals is to raise funds through major gifts each year. The Foundation's new Grateful Patient Program is one way in which we hope to secure major gifts, as your patients are the most valuable and likely source of potential contributions to The Foundation.

The Grateful Patient Program has been established to enable each of us to provide the opportunity for our patients to consider a gift to The Thoracic Surgery Foundation. This can be done in a manner which makes it the patient's choice to approach The Foundation, rather than our asking them directly. The Foundation's new Grateful Patient brochure explains the program in detail and is a useful tool in communicating with a grateful patient. The brochure can be placed in your waiting room for patients to take if they choose to. Or, should patients ask you directly how they can express their thanks for your care, suggest the Grateful Patient Program and give them a brochure. Depending on what you know about a patient and the relationship you have with him or her, you may wish to directly ask them to consider a gift as a grateful patient to The Foundation. The Foundation staff can help you develop a strategy to accomplish this.

To obtain copies of the Grateful Patient brochure, please contact Lainie Castle at 312-464-6100 (telephone), 312-527-6635 (fax), or lcastle@sba.com (E-mail). Sustaining our programs depends on individual gifts. Your support of the Grateful Patient Program helps The Foundation provide ongoing research and education programs which ultimately benefit your patients. Thank you in advance for your thoughtful participation in this program. 